\title{
Editorial
}

\section{Une Bouteille à la mer}

Au seuil d'une nouvelle décennie--déjà la fin du siècle, déjà l'approche du nouveau millénium--comment estimer l'apport intellectuel ainsi que social d'une initiative telle que la nôtre? comment justifier les énergies et les dépenses requises par le lancement d'une revue qui rassemble des textes de critique littéraire et de poésie? Nos buts sont sans doute nobles: stimuler le discours intellectuel, établir des antennes de communication entre différentes universités, abattre la mentalité de «tour d'ivoire», encourager l'esprit créateur, libérer l'élan critique, bref: servir, cultiver, éduquer! Cet effort est en essence une oeuvre de "charité». «L'homme est un animal qui secrète l'amour,» nous affirme André Malraux. Assurément il entend par cela non seulement l'homme qui pense, mais en particulier celui dont la pensée se revêt d'action. Notre engagement veut également contribuer une mesure de synergie à l'élargissement de la conscience sociale.

Nous sommes loin de cette utopie rêvée de Paul Valéry: «une société de l'esprit», c'est-à-dire l'esprit universel uni, fort, porteur garant de la paix sociale. Quelles richesses de poésie dans les dialogues socratiques, dans les correspondances des années 30 entre de Madariaga, Huxley, Freud, Einstein! Dans l'Europe de 1992, ce rêve renaît, tel un phénix d'un feu de violence, pour mettre fin à jamais aux luttes intestinales des hommes. Dans ce contexte, notre entreprise se plaît donc à s'engager à cette re-naissance, à se dresser contre le primitif et pour l'esprit.

Il faut parier contre l'incertain... Qui aurait pensé que de petites publications éphémères, telles la Conque, l'Ermitage, le Phénix, se seraient inscrites dans 1'histoire littéraire française parce que leurs pages, jadis pures, maintenant fragiles et jaunies d'âge, avaient recueilli les premiers rêves artistiques d'un Louÿs, d'un Valéry, d'un Gide! D'ailleurs, qu'aurait été le prix payé en espèce intellectuelle, pendant et immédiatement après le carnage de la deuxième guerre mondiale, sans les revues littéraires de résistance ultramontaine et d'outre-mer: $V V V$ aux Etats-Unis, Labyrinthe en Suisse, Sud en Argentine? La perte aurait été sans doute immense, et immense aussi le vide. 
Il faut parier... Patrick Modiano compare le lancement d'un écrit littéraire à une voix radiodiffusée dans la nuit: qui sait s'il y aura des auditeurs au-delà, dans les ténèbres? A cet optimisme timide, je préfere l'image, me semble-til plus résolue, de Vigny: une bouteille à la mer qui, après les tempêtes, après les ballottements, les «tohus-bohus triomphants", après les vagabondages sur les vastes solitudes, atteindra certainement son port. Multiplions donc les lancements dans le «poème de la mer» et qui sait quels «archipels sidériques» on verra!

Sergio Villani

(Université York)

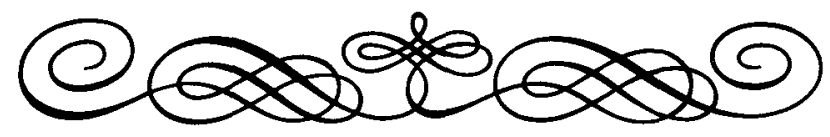

